\section{Wegener polar institute}

SIR - On page 267 of Nature of 27 May 1982, the function and significance of the "Wissenschaftsrat" in the federal system of West Germany is described. There is, however, a serious mistake as far as polar research is concerned.

The article states: "the council was . . . influential in the decision that the new Alfred Wegener research centre for polar research should be located at Bremen rather than at Kiel"'. This is wrong. The comments of the Wissenschaftsrat itself on the question of where to locate the polar institute, as well as many reports in all German newspapers, show that the Wissenschaftsrat favoured Kiel as the site for the new polar research institute.

The reasons for the decision of the Wissenschaftsrat was that Kiel had been the centre of oceanography for more than 100 years. The Institute of Oceanography at the University of Kiel ranks among the most important research centres of its kind in Europe. Kiel University disposes a considerable amount of relevant research potential in other scientific institutes which have for long been performing oceanographic research work together with our Institute of Oceanography on nearly every ocean in the world.

The decision of the then government of West Germany in favour of the polar research institute being located at Bremen was definitely taken against the recommendation of the Wissenschaftsrat and has to be judged according to criteria other than scientific ones.

V. BAGAN

Präsidium der Universität Kiel,

Kiel, FRG

\section{Future of universities}

SIR - As the registrar of the university forced to think most radically about its future developments and purposes, I was naturally interested in your article on the future agenda for the next chairman of the University Grants Committee (UGC) (Nature 300, 301-302; 1982).

Not all British universities seek to imitate Oxbridge. The very first annual report of the first Vice-Chancellor of the University of Salford stated that "in its concern to be seen as equal [to other universities], the university must not accept that all the virtues rest in Oxbridge or in the great provincial universities or in the new foundations of the early ' $60 \mathrm{~s}$. Salford must not become a pale shadow of what others already are".

My university has for a considerable time been seeking to have accepted a different ideal - and not that of Imperial College, excellent though that institution is seen to be. The truth as you clearly imply later in your article is that universities are judged, except for a very, very few cases, by the Oxbridge intellectual and academic model - the most grievous mistake that those in charge of the university system could have made. But the general coherence and thrust of your otherwise trenchant plea for innovation and well-directed change may be undermined by a less than scrupulous regard for the facts.

I really do think that you have distorted almost beyond recognition the relationship between UCCA and the universities. My own salary may be paid with the aid of a computer. It is not, however, (I trust) the chance product of some random process, any more than is the computer-generated letter of offer or indeed rejection which is sent to candidates for admission to universities. University selectors are firmly in control of the choice of students: and it does you no credit to promulgate innuendoes to contrary effect.

Your arguments since mid-1979 for institutional diversity, for incentives and for innovation have been a powerful indictment of the way in which the university system, with the connivance of the government, has been allowed to ignore the real question which the government belatedly and for all the wrong reasons set both itself, the UGC and the universities in 1981. There is as yet no sign of any real change in the underlying consensus - and complacency - on which the UGC gambled so heavily in July 1981.

University of Salford, UK

S.R. BOSWORTH

\section{Friend or FoE?}

SIR - I wish to protest in the strongest possible terms at your abuse of editorial privilege in respect of the two editorials "How to get off the MX hook" and "Inventing the wheel" in Nature of 23/30 December 1982 (pages 671-672).

On the one hand anyone who can write "The ideal. . . would be that missiles such as $M X$ should be made . . invulnerable ..." has no conception of the true meaning of the word ideal. In an ideal world there would be no missiles, $M X$ or otherwise. The manufacture and disposition of any such offensive weapons is a political issue - not a scientific oneand any discussion of these matters has no place in a scientific journal.

Again I would have thought that the editor of a journal so quaintly named as Nature would have hesitated to criticize the "Friends of the Earth" in this respect. Nor is it proper to deride their views editorially. Whilst the engineering design of these reactors may be above reproach, which I doubt, their construction in the United Kingdom is certainly open to criticism on both economic and ecological grounds.

Rickmansworth, Herts, UK

\section{Earthquake light phenomena}

SIR - During the General Assembly of the European Seismological Commission and the meeting of the Subcommission on Earthquake Prediction Research at Leeds, on 27 August 1982, the "Project on Collection and Evaluation of Data on Earthquake Light Phenomena" was initiated.

The true nature of earthquake lights (EQL) remains obscure. Thousands of reports on them are available, and a few drawings and even photographs have been obtained, but the origin of EQLs is still unknown. Apart from studies in the 1930s and 1940s, no systematic study of an EQL has been made.

The first objective of the new project is the collection and analysis of old (historic) and recent EQL-data from all over the world. Particularly important are the relationships between the occurrence of $E Q L$ and the magnitude (and focal depth) of the earthquake.

In many cases EQL have appeared before impending shocks, not only during and/or after them. Hence the second aim of the project, the rapid publication of any observations, so that the data are available for all those dealing with earthquake prediction.

Readers are invited to send reports of any possible $E Q L$ phenomena to me at the address given below.

P. HÉDERVARI

Georgiana Observatory,

H 1023 Budapest,

Arpád fejedelem úta 40-41, Hungary

\section{Seeing stars}

SIR - Why single out the BBC's breakfasttime astrologer for a public upbraiding? (Opinion, Nature 20 January p.184). Why not go the whole way and include, inter alia, politicians, union leaders, captains of industry, Bobby Robson, and (worst of all) economists? My licence fee is continually being dissipated to allow all of them to make the most incredibly inaccurate predictions. I couldn't take the harsh reality of it all until, rather than turning to alcohol, I began to see the funny side of things. I was even (dare I say it) laughing occasionally! But now I read words like "hoodwinked", "public dis-service", "pernicious". Now I'm hopelessly lost, can anybody help me?

Sorry, I think the Great British Public $(G B P)$ is a little more discerning than you would like to think. Even Nature readers know when things are being taken a little bit too seriously.

Frank H. AlleN

University Chemical Laboratory,

Cambridge, UK 